\title{
Interleukin-17A and heparanase promote angiogenesis and cell proliferation and invasion in cervical cancer
}

\author{
QIONGYING LV ${ }^{1 *}$, KEJIA WU $^{1 *}$, FULIN LIU ${ }^{2}$, WANRONG WU ${ }^{2}$, YUROU CHEN $^{2}$ and WEI ZHANG ${ }^{1}$ \\ ${ }^{1}$ Department of Gynaecology, Zhongnan Hospital of Wuhan University, Wuhan, Hubei 430071; \\ ${ }^{2}$ The First Department of Gynaecology, Renmin Hospital of Wuhan University, Wuhan, Hubei 430060, P.R. China
}

Received January 26, 2018; Accepted July 12, 2018

DOI: 10.3892/ijo.2018.4503

\begin{abstract}
Interleukin-17A (IL-17A) is a CD4 T-cell-derived pro-inflammatory cytokine that is involved in human cervical tumorigenesis. Heparanase (HPSE) is an endo-glycosidase expressed in mammals, which has been confirmed to be associated with cervical cancer invasion. In the present study, it was hypothesized that IL-17A and HPSE are key proteins promoting tumor angiogenesis and cell proliferation and invasion in cervical cancer. The expression of IL-17A and HPSE in cervical cancer tissues was detected by immunohistochemical staining. In addition, the expression of IL-17A and HPSE was down- and upregulated via RNAi and human recombinant proteins, and MTT and Transwell assays were performed to examine cervical cancer cell proliferation and invasion, respectively. Flow cytometry analysis was also performed to detect cell cycle distribution, and the levels of target mRNA and protein were evaluated by reverse transcriptionquantitative polymerase chain reaction and western blotting, respectively. IL-17A and HPSE were highly expressed in cervical cancer tissues, and microvessel density was notably higher in the IL-17A-positive group. IL-17A and/or HPSE recombinant protein promoted the proliferation and invasion of cervical cancer cells, increased the proportion of cells in the G2/M phase, and enhanced the mRNA and protein expression of human papillomavirus E6, P53, vascular endothelial growth factor and CD31, whereas downregulation of IL-17A and/or HPSE exerted the opposite effects. Furthermore, downregulation of IL-17A and/or HPSE was found to inhibit the expression of nuclear factor (NF)- $\mathrm{KB}$ P65. In summary, IL-17A and HPSE may promote tumor angiogenesis and cell proliferation and invasion in cervical cancer, possibly via the NF- $\mathrm{KB}$ signaling
\end{abstract}

Correspondence to: Professor Wei Zhang, Department of Gynaecology, Zhongnan Hospital of Wuhan University, 169 Donghu Road, Wuchang, Wuhan, Hubei 430071, P.R. China

E-mail: zw6676@163.com

${ }^{*}$ Contributed equally

Key words: cervical cancer, interleukin-17A, heparanase, angiogenesis, proliferation, invasion pathway. These findings may lead to the identification of new diagnostic markers and therapeutic targets.

\section{Introduction}

Cervical cancer is the fourth most common cancer in women worldwide, with an estimated 527,600 new cases and 265,700 deaths reported in 2012 (1). Although the association between persistent high-risk human papillomavirus (HPV) infection and the development of cervical cancer has been demonstrated by clinical epidemiology, molecular and functional studies, the specific molecular network mechanisms underlying the transition from HPV infection to tumorigenesis have not been fully elucidated. Therefore, there is an urgent clinical need to explore the potential mechanisms underlying cervical tumorigenesis and identify novel tumor markers and treatment targets, in order to ultimately prolong survival and improve the quality of life of the patients.

Interleukin-17 (IL-17) is a CD4 T-cell-derived proinflammatory cytokine, initially referred to as CTLA-8 (2). IL-17A plays an important role in adaptive immune response and is a mediator of chronic inflammation and autoimmune diseases $(3,4)$. The IL-17 receptor (IL-17R) is widely expressed on various cells, including macrophages, granulocytes, T cells, fibroblasts and endothelial cells, among others; thus, IL-17A acts on various cell types to exert its biological effects.

Recent studies have demonstrated that IL-17A promotes tumor progression in several types of cancer, such as colorectal (5), lung (6), breast (7), gastric (8) and hepatocellular carcinoma (9). Thus, IL-17 is considered as an important mediator of inflammation-related cancers (10); it can also induce the production of several inflammatory factors, including tumor necrosis factor- $\alpha$, IL-6 and IL-1 $\beta$ (11), which have been implicated in the development of tumors. IL-17A may also promote vascular endothelial growth factor (VEGF) secretion and tumor angiogenesis, as well as cell invasion and metastasis $(12,13)$.

Heparanase (HPSE) is an enzyme that acts both on the cell surface and within the extracellular matrix (ECM) to degrade polymeric heparan sulfate molecules into shorterchain oligosaccharides, thereby activating macrophages to release inflammatory factors and chemokines, and ultimately promoting tumor cell growth (14). It has been demonstrated that HPSE is expressed in several malignancies (15-17), is associated 
with tumor progression and prognosis, and is involved in the regulation of tumor-related processes, such as angiogenesis, inflammation, tumor cell invasion and metastasis $(18,19)$. According to the literature, IL-17A and HPSE have been found to be associated with tumor and inflammation, and mediate inflammation-related tumor development.

Our previous studies confirmed that the genotypes of IL-17A rs2275913 may play an important role in the development of cervical cancer, particularly in patients with HPV-16 or HPV-18 infection (20). Moreover, it has been confirmed that HPSE silencing significantly reduced the invasiveness of cervical cancer cells (21). Based on this previous research, the present study further analyzed the association between IL-17 and microvessel density (MVD) in cervical cancer by immunohistochemistry. Immunohistochemistry, Transwell and MTT assays and flow cytometry were performed to study the potential roles of IL-17A and HPSE in the development of cervical cancer, as well as the underlying molecular mechanisms, with the aim of providing a theoretical molecular basis for therapeutic targeting.

\section{Materials and methods}

Ethics statement. The present study was approved by the Ethics Committee of Zhongnan Hospital of Wuhan University. The human cervical tissue samples used in this study were obtained from patients following written informed consent.

Cell lines and samples. A total of 80 pairs of samples were obtained from patients with primary cervical cancer who had undergone surgery without chemotherapy or radiotherapy at Zhongnan Hospital of Wuhan University between March 2015 and March 2017. The diagnosis of cervical cancer was confirmed by pathological examination, and adjacent normal cervical tissues ( $>3 \mathrm{~cm}$ away from the tumor) were used as controls. The human cervical cancer cell lines HeLa and SiHa were obtained from the Cell Bank of the Chinese Academy of Sciences (Shanghai, China) and cultured in DMEM (Gibco; Thermo Fisher Scientific, Shanghai, China) containing 10\% FBS (HyClone; GE Healthcare, Logan, UT, USA).

Immunohistochemistry. Immunohistochemistry was performed as previously described (22). Briefly, the cervical tissues were dissected, fixed in $4 \%$ paraformaldehyde, embedded in paraffin, sectioned at a thickness of $\sim 7 \mu \mathrm{m}$, deparaffinized, rehydrated, subjected to antigen retrieval in a microwave oven and probed with primary rat antibodies against IL17A (sc-374218), HPSE (sc-515935) and CD31 (sc-71872) (mouse monoclonal antibodies, 1:100, Santa Cruz Biotechnology, Inc., Santa Cruz, CA, USA). Secondary antibodies combined with streptavidin-horseradish peroxidase (sc-516102, 1:100; Santa Cruz Biotechnology, Inc.) were used to detect IL-17A, HPSE and CD31 expression. In negative controls, primary antibodies were omitted and phosphate-buffered saline (PBS; pH 7.4) was used instead. To analyze the results, the sections were examined and images were captured with an Olympus BX-40 microscope (Olympus Corp., Melville, NY, USA).

Transfection of plasmids. Pre-designed shRNA against HPSE and IL-17A and negative control shRNA were purchased from GenePharma (GenePharma Co., Ltd., Shanghai, China). The
shRNA were transfected into cells seeded on 6-well plates at a density of 10,000 cells/well, as described previously (23). Briefly, after $24 \mathrm{~h}$ of culture in DMEM, the cells were transfected with the HPSE, IL-17A and negative control shRNA at a final concentration of $10 \mathrm{nM}$ using Lipofectamine ${ }^{\mathrm{TM}} 3000$ (Invitrogen; Thermo Fisher Scientific, Carlsbad, CA, USA) according to the manufacturer's protocol. At $48 \mathrm{~h}$ post-transfection, cells were harvested for further experiments.

$R N A$ isolation and reverse transcription-quantitative polymerase chain reaction $(R T-q P C R)$ analysis. Total RNA was extracted from cell lines with TRIzol ${ }^{\circledR}$ reagent (Invitrogen; Thermo Fisher Scientific) according to the manufacturer's protocol. cDNA was synthesized by reverse transcription of the total RNA. RT-qPCR was performed using a SYBR Green Real Time PCR Kit (Toyobo Co., Ltd., Osaka, Japan) in a 10- $\mu 1$ reaction volume, which contained $1 \mu \mathrm{l}$ cDNA template, $0.2 \mu \mathrm{l}$ of each primer, $3.6 \mu \mathrm{l}$ DEPC- $\mathrm{H}_{2} \mathrm{O}$, and $5 \mu \mathrm{l}$ SYBR Green dye, using an ABI Step One Plus ${ }^{\mathrm{TM}}$ Real-Time PCR System (Applied Biosystems; Thermo Fisher Scientific). The cycling conditions for the amplification of genes were as follows: Initial denaturation at $95^{\circ} \mathrm{C}$ for $30 \mathrm{sec}$, followed by 40 cycles of denaturation at $95^{\circ} \mathrm{C}$ for $5 \mathrm{sec}$, annealing at $60^{\circ} \mathrm{C}$ for $10 \mathrm{sec}$ and elongation at $72^{\circ} \mathrm{C}$ for $30 \mathrm{sec}$. The relevant primers are listed in Table I.

Western blot analysis. Western blot analysis was performed as described previously (24). Briefly, total protein was extracted from cells using radio-immunoprecipitation assay lysis buffer (Beyotime Institute of Biotechnology, Haimen, China) supplemented with protease and phosphatase inhibitors (SigmaAldrich; Merck KGaA, St. Louis, MO, USA). Equal amounts of protein samples were loaded and separated by $10 \%$ SDS-PAGE, prior to being electrophoretically transferred to $0.44-\mu \mathrm{m} \mathrm{PVDF}$ membranes (Millipore, Bedford, MA, USA) at $250 \mathrm{~mA}$ for $60 \mathrm{~min}$ on ice. The non-specific binding sites on the membrane were blocked with $5 \%$ fat-free milk in TBS containing $0.1 \%$ Tween-20 at room temperature for $2 \mathrm{~h}$. Then, the membranes were incubated with a primary antibody (Santa Cruz Biotechnology, Inc.) at $4^{\circ} \mathrm{C}$ overnight and developed with a secondary antibody conjugated to HRP (Santa Cruz Biotechnology Inc.) at room temperature for $1.5 \mathrm{~h}$. Finally, the proteins were visualized using enhanced chemiluminescence luminol reagent (PerkinElmer, Inc., Boston, MA, USA) and band intensities were quantified using ImageJ software (National Institutes of Health, Bethesda, MD, USA). GAPDH was used as a loading control.

Cell cycle distribution analysis. At $48 \mathrm{~h}$ after transfection with shRNA or treatment with recombinant proteins (HPSE, ab232817, ProSpec-Tany; IL-17A, ab9567, Abcam, Cambridge, UK), the cells were detached and fixed with $70 \%$ ethanol at $-20^{\circ} \mathrm{C}$ overnight. Subsequently, the cells were collected by centrifugation at $500 \mathrm{x} \mathrm{g}$ for $5 \mathrm{~min}$, washed with PBS and incubated with $25 \mu \mathrm{g} / \mathrm{ml}$ RNase A and $50 \mu \mathrm{g} / \mathrm{ml}$ propidium iodide (PI) for $30 \mathrm{~min}$ in the dark. In a total of $2 \times 10^{4}$ cells, the cell cycle distribution was mapped by flow cytometry (BD Biosciences, Franklin Lakes, NJ, USA) under excitation and emission wavelengths of 488 and $525 \mathrm{~nm}$, respectively.

Cell proliferation. CCK- 8 assays were performed to evaluate cell proliferation. For the CCK-8 assays, $5 \times 10^{3}$ cells/well 
Table I. The relative primers of target genes.

\begin{tabular}{|c|c|c|c|}
\hline Gene & & Sequence & Size (bp) \\
\hline$\beta$-actin & $\begin{array}{l}\text { Forward } \\
\text { Reverse }\end{array}$ & $\begin{array}{l}\text { 5'-CACGATGGAGGGGCCGGACTCATC-3' } \\
\text { 5'-TAAAGACCTCTATGCCAACACAGT-3' }\end{array}$ & 240 \\
\hline VEGF & $\begin{array}{l}\text { Forward } \\
\text { Reverse }\end{array}$ & $\begin{array}{l}\text { 5'-AAGGAGGAGGGCAGAATCAT-3' } \\
\text { 5'-ATCTGCATGGTGATGTTGGA-3' }\end{array}$ & 226 \\
\hline CD31 & Forward & 5'-GTGCTGCAATGTGCTGTGAAT-3' & 180 \\
\hline HPSE & $\begin{array}{l}\text { Forward } \\
\text { Reverse }\end{array}$ & $\begin{array}{l}\text { 5'-ATCAATGGGTCGCAGTTAG-3' } \\
\text { 5'-AGCATCTTAGCCGTCTTTC-3' }\end{array}$ & 128 \\
\hline P53 & $\begin{array}{l}\text { Forward } \\
\text { Reverse }\end{array}$ & $\begin{array}{l}\text { 5'-CCACCATCCACTACAACTACAT-3' } \\
\text { 5'-AAACACGCACCTCAAAGC-3' }\end{array}$ & 135 \\
\hline IL17 & $\begin{array}{l}\text { Forward } \\
\text { Reverse }\end{array}$ & $\begin{array}{l}\text { 5'-CCACCTCACCTTGGAATCTC-3' } \\
\text { 5'-CCCACGGACACCAGTATCTT-3' }\end{array}$ & 220 \\
\hline
\end{tabular}

VEGF, vascular endothelial growth factor; HPSE, heparanase; IL, interleukin.

Table II. Association between IL-17A and HPSE.

\begin{tabular}{lcccc}
\hline & \multicolumn{2}{c}{ HPSE } & & \\
\cline { 2 - 3 } & Positive & Negative & r & P-value \\
\hline IL-17A & & & & 0.01 \\
Positive & 44 & 12 & 0.286 & \\
Negative & 12 & 12 & & \\
\hline
\end{tabular}

HPSE, haparanase; IL, interleukin.

transfected with shRNA or treated with recombinant proteins were seeded into 96-well plates, cultured in DMEM for $72 \mathrm{~h}$ and incubated for another $2 \mathrm{~h}$ after CCK-8 (10 $\mu \mathrm{l}$; American Type Culture Collection, Manassas, VA, USA) was added into each well. The cell proliferation status was determined from the absorbance of culture plates using ELISA readers (Tecan, Port Melbourne, Australia) at $450 \mathrm{~nm}$ after $24 \mathrm{~h}$.

Transwell assays. Transwell assays were used to examine cell invasion. At $24 \mathrm{~h}$ after transfection with shRNA or treatment with recombinant proteins, $8 \times 10^{4}$ cells/well were cultured in $200 \mu \mathrm{l}$ serum-free DMEM and then transferred to an upper Transwell chamber containing an $8-\mu \mathrm{m}$ pore size membrane coated with Matrigel (BD Biosciences), while the lower chamber was filled with $800 \mu \mathrm{l}$ DMEM supplemented with $10 \%$ FBS. After $48 \mathrm{~h}$, the invaded cells on the lower side of the membrane were fixed in methanol and stained with $0.1 \%$ crystal violet solution (SigmaAldrich; Merck KGaA, Darmstadt, Germany). The cells were then counted under a microscope (Olympus Corp., Tokyo, Japan).

Statistical analysis. Statistical analyses were conducted with SPSS v.22.0 software (IBM Corp., Armonk, NY, USA). Data are expressed as the mean \pm standard error of $\geq 3$ independent experiments. The correlation between variables was determined using Spearman's correlation. Differences between
Table III. Association between IL-17A and MVD.

\begin{tabular}{lcccc}
\hline & & \multicolumn{3}{c}{ MVD } \\
\cline { 3 - 5 } & Patient no. & $\overline{\mathrm{x}} \pm \mathrm{s}$ & $\mathrm{t}$ & P-value \\
\hline IL-17A & & & & 0.000 \\
Positive & 56 & $41.567 \pm 16.72$ & & \\
Negative & 24 & $32.332 \pm 8.31$ & 6.085 & \\
\hline
\end{tabular}

IL, interleukin; MVD, microvessel density.

groups were evaluated using the Student's t-test or one-way analysis of variance, and $\mathrm{P}$-values $<0.05$ were considered to indicate statistically significant differences.

\section{Results}

IL-17A and HPSE are highly expressed in cervical cancer and may promote tumor angiogenesis. According to the results of immunohistochemistry, IL-17A was mainly expressed in cancer cells, with the staining mainly distributed in the cytoplasm; HPSE staining was also distributed in the cytoplasm, as well as being occasionally visible in the nucleus (Fig. 1A). The positive expression rates of IL-17A and HPSE in cervical cancer tissues were both $\sim 70 \%$, and according to the correlation analysis, there was a significant positive correlation between the two (Fig. 1B, Table II). Among patients with cervical cancer, there were 56 cases with IL-17A-positive expression, in which the MVD was $41.567 \pm 16.72$, while in the 24 cases with IL-17A-negative expression the MVD was $32.332 \pm 8.31$. The MVD was significantly higher in the IL-17A-positive group compared with that in the IL-17A-negative group $(\mathrm{P}<0.001$; Fig. 1C, Table III).

IL-17A and HPSE promote cell proliferation and invasion. HPSE shRNA experimental groups were established as 

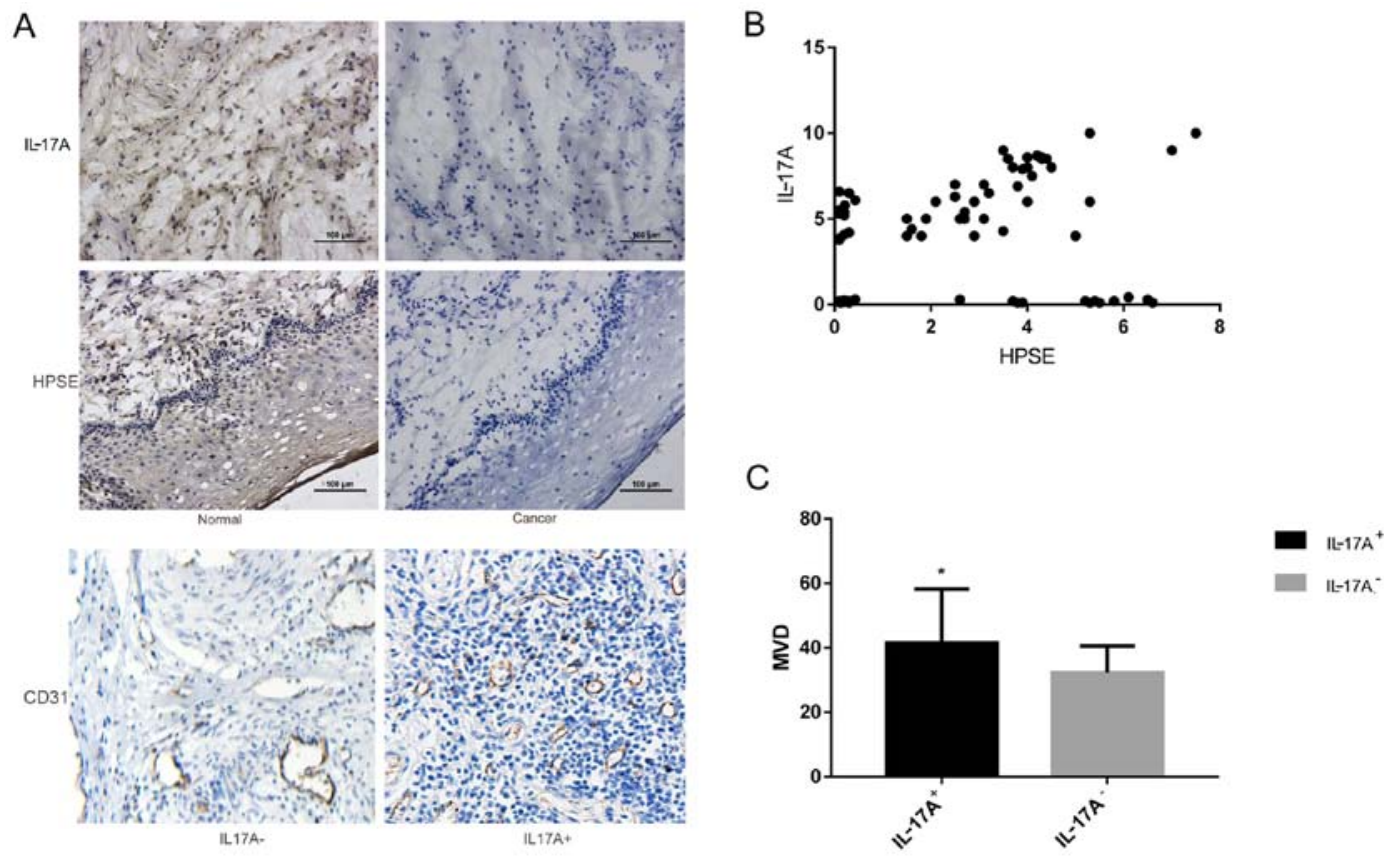

Figure 1. (A) The expression levels of IL-17A, HPSE and CD31 in cervical cancer were detected by immunohistochemistry (magnification, x100). (B) Correlation between IL-17A and HPSE in cervical cancer. (C) MVD in the IL-17A ${ }^{+}$and IL-17A- cervical cancer tissues. IL, interleukin; HPSE, heparanase; MVD, microvessel density.
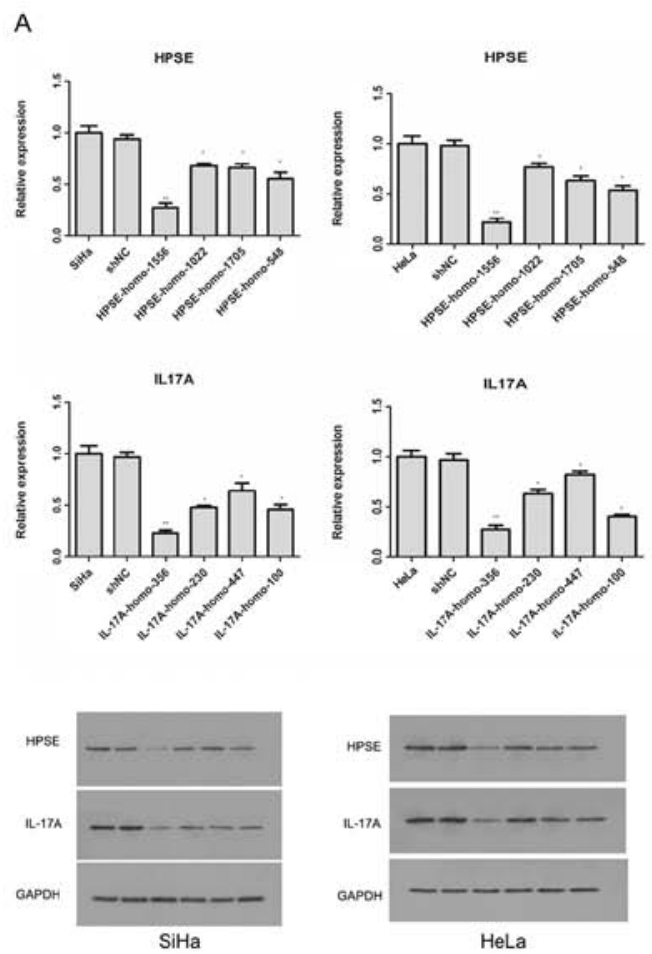
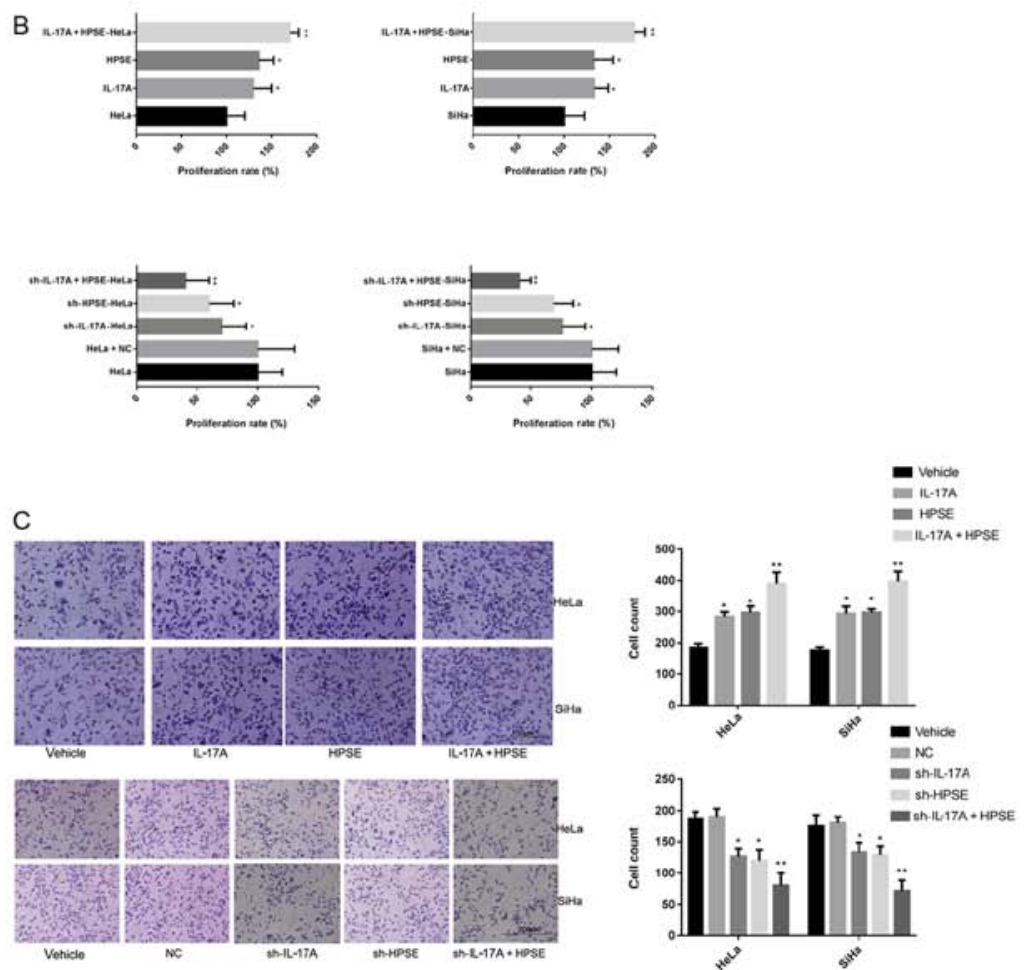

Figure 2. (A) Histogram and grayscale results of the expression of target mRNA and proteins in SiHa and HeLa cervical cancer cells following transfection with different IL-17A and HPSE plasmids for $48 \mathrm{~h}$. (B) Histogram results of the proliferation rates of SiHa and HeLa cervical cancer cells following treatment with recombinant protein or shRNA of IL-17A and HPSE for $48 \mathrm{~h}$. (C) Invasion of cervical cancer cells detected using a Transwell assay; the image shows the number of cells that invaded to the lower side of the membrane after transfection with different IL-17A and HPSE plasmids for $48 \mathrm{~h}$. The data shown are representative of multiple experiments (presented as the mean \pm standard deviation, $\mathrm{n}=10 ;{ }^{*} \mathrm{P}<0.05$, ${ }^{* *} \mathrm{P}<0.01$ ). IL, interleukin; HPSE, heparanase.

follows: HPSE-1556, HPSE-1022, HPSE-1705, HPSE-548, negative control (NC) and blank control groups. IL-17A shRNA experimental groups were established as follows: IL-17A-356, IL-17A-230, IL-17A-447, IL-17A-100, NC and blank control groups. The levels of IL-17A and HPSE mRNA in both SiHa and HeLa cells in the HPSE-1556 and IL-17A-356 groups were the lowest, indicating that the two shRNA plasmids had the best silencing effect on the relative genes. Western blot analysis 

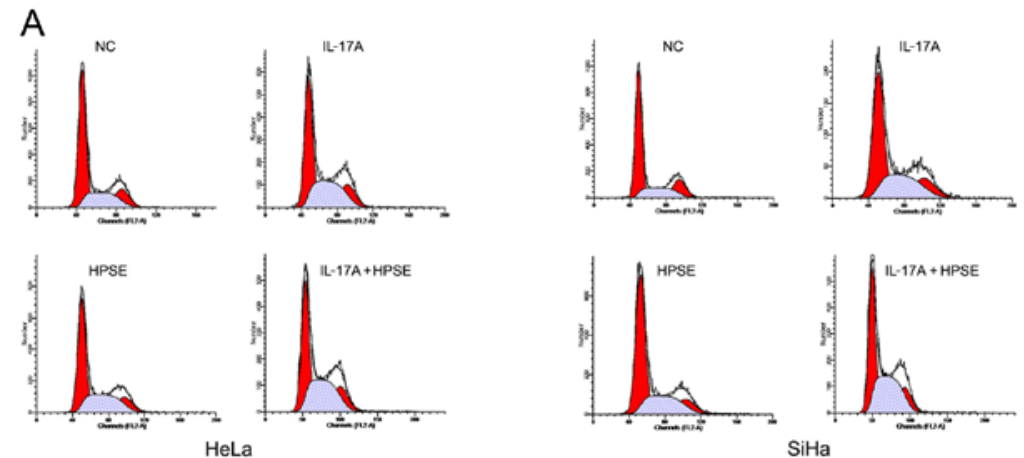

B
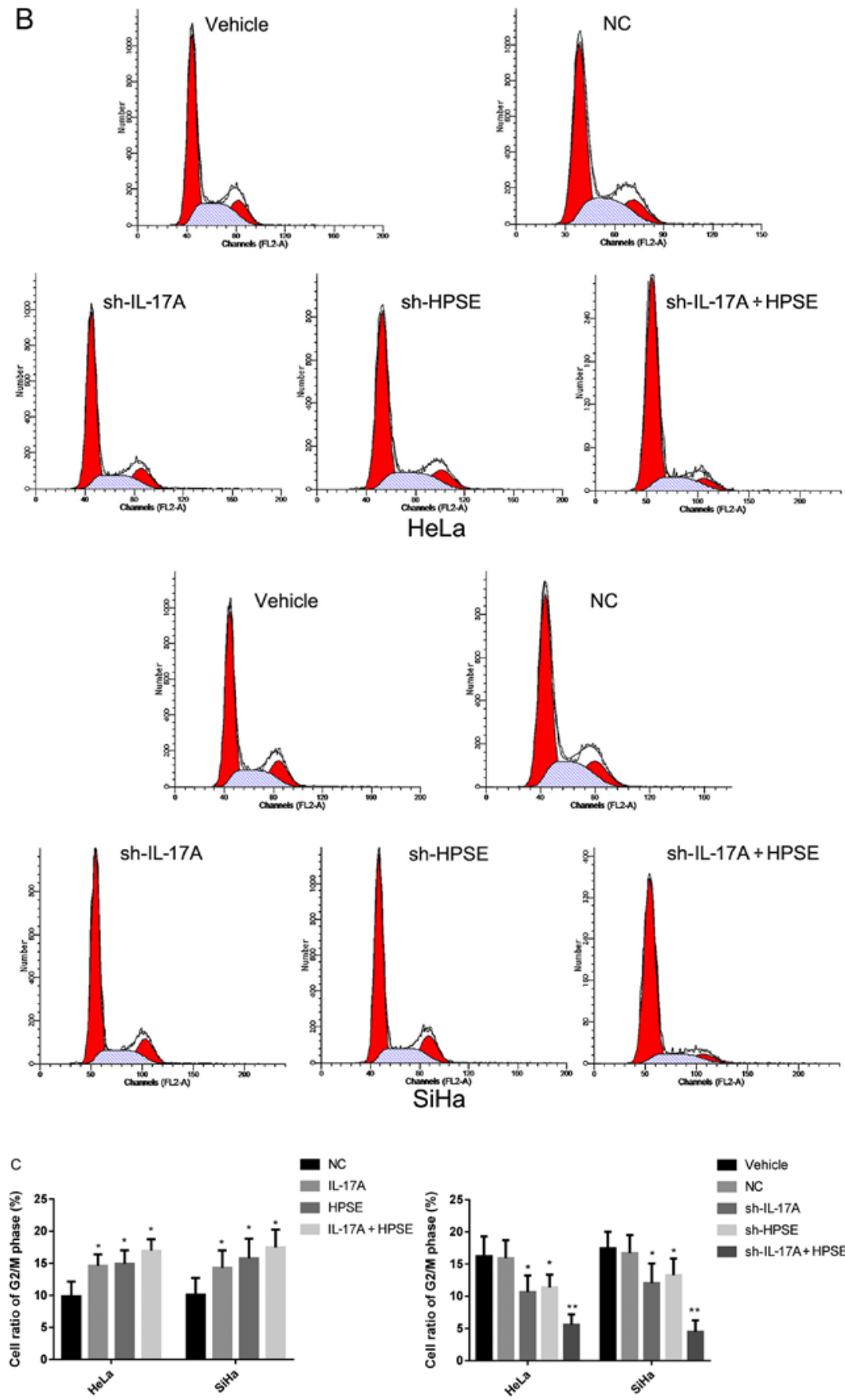

Figure 3. (A) Cell cycle distribution measured by flow cytometry following target protein upregulation. The left flow chart shows the proportion of cells in the G2/M phase in the HeLa, IL-17A-HeLa, HPSE-HeLa and IL-17A + HPSE-HeLa cell groups. The right flow chart shows the proportion of cells in the G2/M phase in the SiHa, IL-17A-SiHa, HPSE-SiHa and IL-17A + HPSE-SiHa cell groups. (B) Cell cycle distribution measured by flow cytometry following target protein knockdown. The upper flow chart shows the proportion of cells in the G2/M phase in the HeLa, NC, IL-17A-HeLa, HPSE-HeLa and IL-17A + HPSE-HeLa cell groups. The lower flow chart shows the proportion of cells in the G2/M phase in the SiHa, NC, IL-17A-SiHa, HPSE-SiHa and IL-17A + HPSE-SiHa cell groups. (C) The relative statistical analysis of parts A and B. IL, interleukin; HPSE, heparanase; NC, negative control. 
yielded the same results (Fig. 2A). SiHa and HeLa cells were treated with recombinant protein (HPSE: $500 \mathrm{ng} / \mathrm{ml}$; IL-17A: $20 \mathrm{ng} / \mathrm{ml}$ ) or shRNA. After $24 \mathrm{~h}$ of incubation, the proliferation rate of cells was measured. The IL-17A and HPSE recombinant proteins were found to promote cell proliferation; moreover, the IL-17A and HPSE recombinant proteins exerted an additive effect; after the IL-17A and HPSE genes were silenced, the cell proliferation rate was significantly decreased, with the inhibition induced by IL-17A and HPSE shRNA co-transfection being the most notable (Fig. 2B). The invasion of cervical cancer cells was detected using a Transwell assay following treatment with recombinant protein or shRNA. It was observed that the numbers of cells invading to the lower chamber in the IL-17A, HPSE and IL-17A + HPSE groups were significantly higher compared with those in the $\mathrm{NC}$ and blank control groups $(\mathrm{P}<0.01)$. Moreover, the number of invaded cells in the sh-IL-17A, sh-HPSE and sh-IL-17A + HPSE groups was significantly lower compared with that in the NC and blank control groups $(\mathrm{P}<0.01)$ (Fig. 2C).

The proportion of cells in the G2/M phase was increased by $I L-17 A$ and HPSE. Cell cycle distribution was measured by flow cytometry. The proportion of cells in the G2/M phase in the IL-17A HeLa, HPSE HeLa and IL-17A + HPSE HeLa cell groups was significantly higher compared with that in the control HeLa cell groups $(\mathrm{P}<0.01)$. These results demonstrated that IL-17A and HPSE recombinant proteins significantly increased the rate of HeLa cell proliferation. The SiHa cell groups exhibited similar changes (Fig. 3A). Conversely, following silencing of IL-17A and/or HPSE in HeLa and SiHa cells, the number of cells in the G2/M phase was significantly reduced compared with the corresponding control groups $(\mathrm{P}<0.01)$. Moreover, IL-17A and HPSE gene silencing exerted an additive effect in inhibiting cell proliferation (Fig. 3B).

IL-17A and HPSE can increase the $M R N A$ and protein levels of HPV E6, CD31, VEGF and P53. Compared with NC cells, the expression levels of HPV E6, CD31, VEGF, HPSE, L17A and P53 in HeLa and SiHa cells were significantly increased following treatment with IL-17 or HSPE recombinant protein $(\mathrm{P}<0.05)$ (Fig. 4A). However, after silencing of HPSE and IL-17A gene expression, the mRNA and protein levels of HPV E6, CD31, VEGF, HPSE and L17A in HeLa and SiHa cells were significantly decreased $(\mathrm{P}<0.05$; Fig. $4 \mathrm{~B})$.

Detection of NF- $\kappa B$ P65 protein expression by western blotting. The expression of the NF- $\kappa \mathrm{B}$ P65 protein in HeLa and SiHa cells was found to be decreased following inhibition of IL-17A or HPSE. However, inhibition of P53 gene expression significantly increased the protein expression of NF- $\mathrm{B}$ P65; compared with the control group, the difference was statistically significant $(\mathrm{P}<0.05$; Fig. 5$)$.

\section{Discussion}

Since Rudolph Virchow identified inflammatory cells in tumor tissue and formulated the hypothesis that tumors may originate from chronic inflammation, the association between tumors and inflammation has become an important focus in the study of tumorigenesis. Inflammation is considered to be a defense mechanism by which the body resists invasion by pathogens. When the inflammatory response initiates an innate immune response, the immune response cells release a range of inflammatory cytokines, such as IL-1, IL-6, IL-17 and IL-23. Furthermore, inflammatory-related transcription factors, such as NF- $\kappa$ B and STAT3, are also activated $(25,26)$. When such an inflammatory microenvironment forms around tumor tissue, it may promote tumor growth.

IL-17A is a recently identified pro-inflammatory cytokine that plays an important role in the development of several chronic inflammatory conditions and cancers by binding to its receptor, IL-17R. The progression from persistent HPV infection to cervical cancer has been associated with an inflammatory microenvironment containing Th17 cells. As a catalyst of heparan sulfate cleavage, HPSE is associated with the shedding of biologically active molecules and remodeling of the ECM, which are involved in the regulation of tumor-related processes, including angiogenesis, cell invasion, metastasis and inflammation (15). HPSE not only promotes cell-to-cell transmission, but also promotes the growth of primary tumor blood vessels and accelerates the migration of tumor cells (27).

Studies to date have demonstrated that IL-17A and HPSE are involved in inflammation and tumorigenesis, and that both are associated with the expression of the HPV E6 protein $(28,29)$. In the present study, recombinant protein stimulation and RNA interference were used to up- and downregulate, respectively, the expression of IL-17A and HPSE in cervical cancer cell lines. The cell proliferation and invasion abilities were significantly enhanced following treatment with recombinant protein, particularly following combined treatment with recombinant IL-17A and HPSE. By contrast, upon downregulation of the expression of HPSE and IL-17A, the cell proliferation and invasion rates were significantly attenuated; this effect was more obvious upon suppression of both genes, suggesting that HPSE and IL-17A can promote the proliferation and invasion of cervical cancer cells, and that their effects are additive.

In order to further investigate the specific mechanisms of action of IL-17A and HPSE in cervical cancer, the expression of HPV E6, VEGF, CD31 and P53 were assessed, and it was observed that they were all upregulated when IL-17A and HPSE were upregulated, and vice versa; moreover, when P53 was inhibited, the expression of both IL-17A and HPSE increased. IL-17A and HPSE regulate the expression of VEGF and CD31, both of which are markers of angiogenesis, and the results of the immunohistochemical examination revealed that MVD was significantly higher in tumor tissues of the IL-17A-positive group compared with the IL-17A-negative group. Therefore, IL-17A and HPSE may promote cervical cancer growth, invasion and metastasis by inducing tumor angiogenesis. The results of the present study are consistent with previously published results $(13,30)$. Yan et al recently demonstrated that loss of histone deacetylase 6 (HDAC6) in mice stimulated the development of IL-17-producing $\gamma \delta$ T cells, indicating that HDAC6 may repress IL-17 production in T cells (31). These results, combined with those of the present study, indicate that inhibition of HDAC6 promotes the expression of IL-17, which may be involved in cervical cancer cell proliferation and invasion, and tumor angiogenesis. However, Lin et al reported that inhibition of HDAC activity specifically 

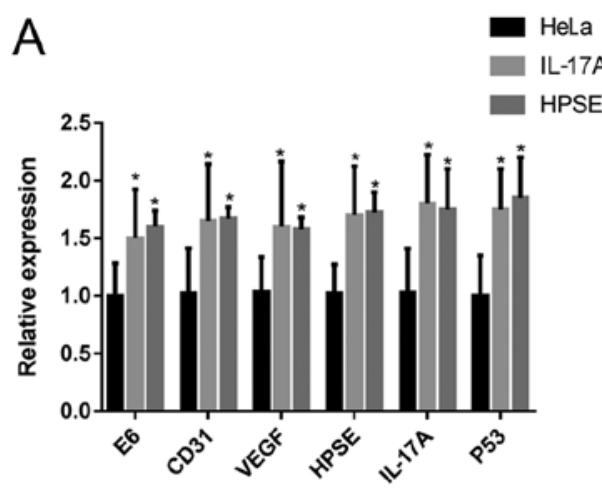
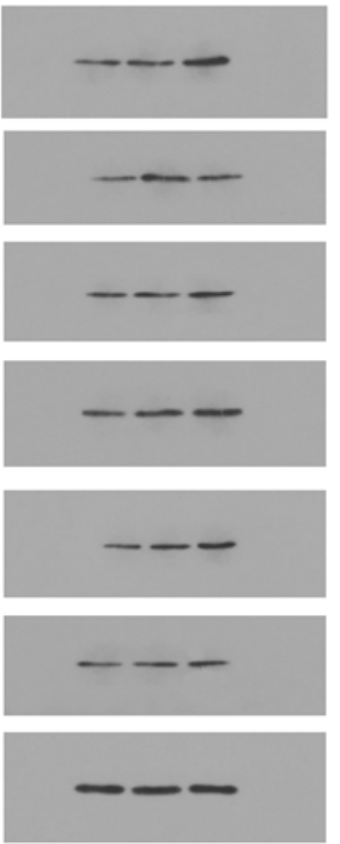

SiHa IL-17A HPSE
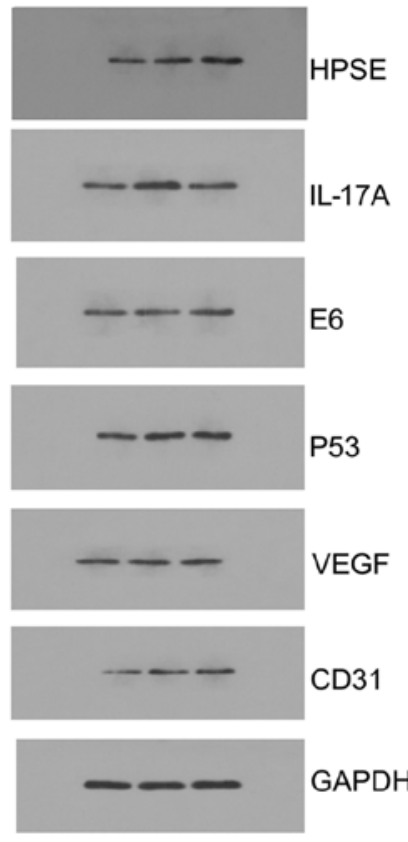

HeLa IL-17A HPSE

$\mathrm{SiHa}$

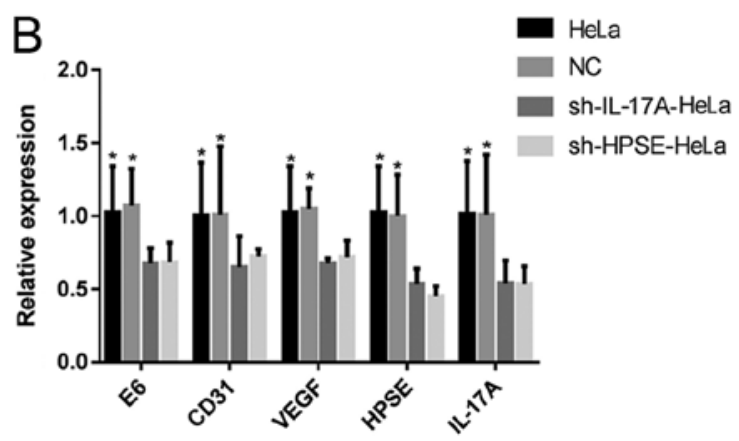

HeLa
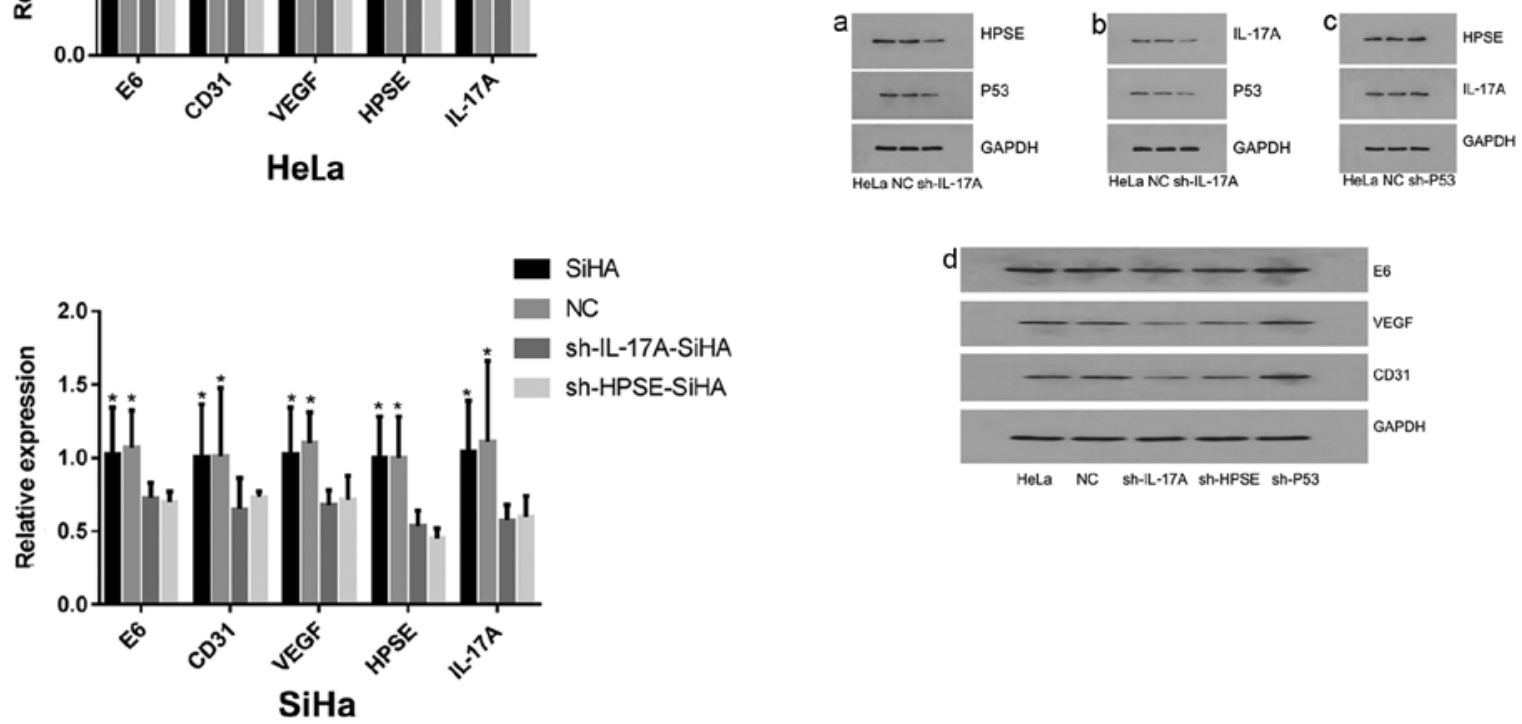

Figure 4. (A) mRNA and protein expression of HPV E6, CD31, VEGF, HPSE, IL-17A and P53 following target protein upregulation. Shown are the histogram results of the relative mRNA levels of HPV E6, CD31, VEGF, HPSE, IL-17A and P53 in HeLa and SiHa cells following treatment with recombinant proteins of IL-17A and HPSE for $48 \mathrm{~h}$. The data shown are representative of multiple experiments; (B) mRNA and protein expression of HPV E6, CD31, VEGF, HPSE and IL-17A in HeLa and SiHa cells following target protein knockdown. Shown are the histogram results of the relative mRNA levels of HPV E6, CD31, VEGF, HPSE and IL-17A in HeLa and SiHa cells following treatment with shRNAs against IL-17A and HPSE for 24 h. The data shown are representative of multiple experiments (presented as the mean \pm standard deviation, $\mathrm{n}=10 ;{ }^{*} \mathrm{P}<0.05,{ }^{* *} \mathrm{P}<0.01$ ). HPV, human papillomavirus; VEGF, vascular endothelial growth factor; HPSE, heparanase; IL, interleukin. 

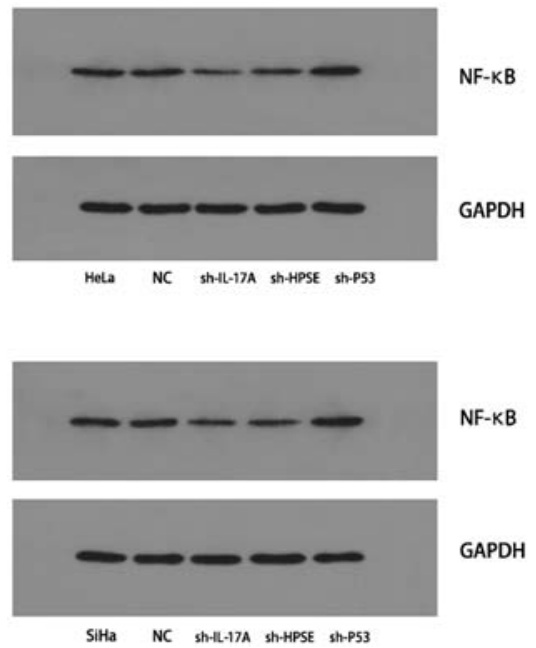

Figure 5. Expression of nuclear factor (NF)-кB p56 in HeLa and SiHa cells following target protein knockdown. HeLa and SiHa cells $\left(1 \times 10^{6}\right.$ cells/well) were treated with sh-HPSE and/or sh-IL-17A or sh-p53 for $24 \mathrm{~h}$, then NF-kB P65 protein levels were determined by western blotting and normalized to the expression of the housekeeping gene GAPDH. HPSE, heparanase; IL, interleukin; NC, negative control.

triggered cervical cancer cell death through interruption of E6 and E7 signaling (32). Therefore, the precise role of HDAC in cervical cancer requires further investigation.

$\mathrm{NF}-\mathrm{\kappa B}$ is a pleiotropic transcription factor that specifically binds to $\mathrm{\kappa B}$ sites on multiple gene promoters to facilitate transcriptional expression (33). In recent years, the role of NF- $\mathrm{KB}$ in tumors has been a focus of numerous studies. NF- $\kappa B$ is at the junction of multiple types of stimulating signals that affect various aspects of the steady state of cells, and it may thereby serve as a mediator of tumor development. In the present study, following inhibition of IL-17A or HPSE, the expression of NF- $\mathrm{KB}$ in SiHa and HeLa cells was significantly decreased. As $\mathrm{NF}-\kappa \mathrm{B}$ is regulated by stimuli such as oxidative stress, bacterial lipopolysaccharide and cytokines, among others, and can regulate the production of pro-inflammatory cytokines, cell surface receptors, transcription factors and adhesion molecules, it was hypothesized that IL-17A may affect the development of cervical cancer through activating the NF- $\mathrm{kB}$ signaling pathway.

However, the present study had several limitations. First, patients were not followed up postoperatively; therefore, survival analysis results were not provided. Second, in the present study, IL-17A and HPSE were found to promote angiogenesis and cell proliferation and invasion in cervical cancer; however, the specific upstream and downstream mechanisms linking IL-17A and HPSE molecules were not investigated in detail. Therefore, we plan to perform cell and animal studies to investigate the exact pathways associated with both IL-17A and HPSE in cervical cancer. Large-scale, well-designed studies elucidating issues such as whether IL-17A can activate the JAK/STAT pathway to regulate angiogenesis and, thus, contribute to cervical carcinogenesis, as well as clinical research trials, are required to fully elucidate the pathogenesis of cervical cancer.

In conclusion, IL-17 appears to promote cell proliferation and invasion and angiogenesis in cervical cancer, which may be enhanced by the additive effect of HPSE. The present and future studies on these molecular aspects are of great value, as they may provide a novel experimental basis and potential clinical targets to improve the treatment and prognosis of patients with cervical cancer.

\section{Acknowledgements}

Not applicable.

\section{Funding}

The present study was supported by Zhongnan Hospital of Wuhan University, Science, Technology and Innovation Seed Fund (grant no. znpy2016040).

\section{Availability of data and materials}

All the datasets collected and analyzed in the present study are available from the corresponding author on reasonable request.

\section{Authors' contributions}

QL and KW performed the experimental work and wrote the manuscript, FL and WW helped collect the clinical samples, YC analyzed the data, WZ designed the study and reviewed the manuscript. All authors discussed the results and approved the final version of the manuscript.

\section{Ethics approval and consent to participate}

The present study was approved by the Ethics Committee of Zhongnan Hospital of Wuhan University. The human cervical tissue samples used in this study were obtained from patients following written informed consent.

\section{Patient consent for publication}

Not applicable.

\section{Competing interests}

The authors declare that they have no competing interests to disclose.

\section{References}

1. Torre LA, Bray F, Siegel RL, Ferlay J, Lortet-Tieulent J and Jemal A: Global cancer statistics, 2012. CA Cancer J Clin 65: 87-108, 2015.

2. Yao Z, Painter SL, Fanslow WC, Ulrich D, Macduff BM, Spriggs MK and Armitage RJ: Human IL-17: A novel cytokine derived from T cells. J Immunol 155: 5483-5486, 1995.

3. Gaffen SL: An overview of IL-17 function and signaling. Cytokine 43: 402-407, 2008.

4. Gerhardt S, Abbott WM, Hargreaves D, Pauptit RA, Davies RA, Needham MR, Langham C, Barker W, Aziz A, Snow MJ, et al: Structure of IL-17A in complex with a potent, fully human neutralizing antibody. J Mol Biol 394: 905-921, 2009.

5. Omrane I, Medimegh I, Baroudi O, Ayari H, Bedhiafi W, Stambouli N, Ferchichi M, Kourda N, Bignon YJ, Uhrhammer N, et al: Involvement of IL17A, IL17F and IL23R polymorphisms in colorectal cancer therapy. PLoS One 10: e0128911, 2015.

6. Xu B, Guenther JF, Pociask DA, Wang Y, Kolls JK, You Z, Chandrasekar B, Shan B, Sullivan DE and Morris GF: Promotion of lung tumor growth by interleukin-17. Am J Physiol Lung Cell Mol Physiol 307: L497-L508, 2014. 
7. Slattery ML, Herrick JS, Torres-Mejia G, John EM, Giuliano AR, Hines LM, Stern MC, Baumgartner KB, Presson AP and Wolff RK: Genetic variants in interleukin genes are associated with breast cancer risk and survival in a genetically admixed population: The Breast Cancer Health Disparities Study. Carcinogenesis 35: 1750-1759, 2014.

8. Dai ZM, Zhang TS, Lin S, Zhang WG, Liu J, Cao XM, Li HB, Wang M, Liu XH, Liu K, et al: Role of IL-17A rs2275913 and IL-17F rs763780 polymorphisms in risk of cancer development: An updated meta-analysis. Sci Rep 6: 20439, 2016.

9. Gomes AL, Teijeiro A, Burén S, Tummala KS, Yilmaz M, Waisman A, Theurillat JP, Perna C and Djouder N: Metabolic inflammation-associated IL-17A causes non-alcoholic steatohepatitis and hepatocellular carcinoma. Cancer Cell 30: 161-175, 2016.

10. Chang SH, Mirabolfathinejad SG, Katta H, Cumpian AM, Gong L, Caetano MS, Moghaddam SJ and Dong C: T helper 17 cells play a critical pathogenic role in lung cancer. Proc Nat Acad Sci USA 111: 5664-5669, 2014.

11. Lin WW and Karin M: A cytokine-mediated link between innate immunity, inflammation, and cancer. J Clin Invest 117: 1175-1183, 2007.

12. Tong Z, Yang XO, Yan H, Liu W, Niu X, Shi Y, Fang W, Xiong B, Wan Y and Dong C: A protective role by interleukin-17F in colon tumorigenesis. PLoS One 7: e34959, 2012.

13. Kulig P, Burkhard S, Mikita-Geoffroy J, Croxford AL, Hövelmeyer N, Gyülvészi G, Gorzelanny C, Waisman A, Borsig L and Becher B: IL17A-mediated endothelial breach promotes metastasis formation. Cancer Immunol Res 4: 26-32, 2016.

14. Meirovitz A, Goldberg R, Binder A, Rubinstein AM, Hermano E and Elkin M: Heparanase in inflammation and inflammationassociated cancer. FEBS J 280: 2307-2319, 2013.

15. Vlodavsky I, Beckhove P, Lerner I, Pisano C, Meirovitz A, Ilan N and Elkin M: Significance of heparanase in cancer and inflammation. Cancer Microenviron 5: 115-132, 2012

16. Boyango I, Barash U, Naroditsky I, Li JP, Hammond E, Ilan N and Vlodavsky I: Heparanase cooperates with Ras to drive breas and skin tumorigenesis. Cancer Res 74: 4504-4514, 2014

17. Fernandes dos Santos TC, Gomes AM, Paschoal ME, Stelling MP, Rumjanek VM, Junior AR, Valiante PM, Madi K Pereira de Souza HS, Pavão MS, et al: Heparanase expression and localization in different types of human lung cancer. Biochim Biophys Acta 1840: 2599-2608, 2014.

18. Poon IK, Goodall KJ, Phipps S, Chow JD, Pagler EB, Andrews DM, Conlan CL, Ryan GF, White JA, Wong MK, et al: Mice deficient in heparanase exhibit impaired dendritic cell migration and reduced airway inflammation. Eur J Immunol 44: 1016-1030, 2014

19. Shteingauz A, Boyango I, Naroditsky I, Hammond E, Gruber M, Doweck I, Ilan N and Vlodavsky I: Heparanase enhances tumor growth and chemoresistance by promoting autophagy. Cancer Res 75: 3946-3957, 2015.

20. Lv Q, Zhu D, Zhang J, Yi Y, Yang S and Zhang W: Association between six genetic variants of IL-17A and IL-17F and cervical cancer risk: A case-control study. Tumour Biol 36: 3979-3984, 2015 .
21. Lü QY, Zhang W, Cheng J, Zhang WT and Zhong YJ: Effect on invasion ability of cervical cancer cells after silence heparanase gene expression in HeLa cells. Zhonghua Fu Chan Ke Za Zhi 48: 532-537, 2013 (In Chinese)

22. Chen RJ, Shun CT, Yen ML, Chou CH and Lin MC: Methyltransferase G9a promotes cervical cancer angiogenesis and decreases patient survival. Oncotarget 8: 62081-62098, 2017.

23. Li X, Song Y, Liu F, Liu D, Miao H, Ren J, Xu J, Ding L, Hu Y, Wang Z, et al: Long non-coding RNA MALAT1 promotes proliferation, angiogenesis, and immunosuppressive properties of mesenchymal stem cells by inducing VEGF and IDO. J Cell Biochem 118: 2780-2791, 2017.

24. Zhu X, Er K, Mao C, Yan Q, Xu H, Zhang Y, Zhu J, Cui F, Zhao W and Shi H: miR-203 suppresses tumor growth and angiogenesis by targeting VEGFA in cervical cancer. Cell Physiol Biochem 32: 64-73, 2013.

25. Fernandes JV, DE Medeiros Fernandes TA, DE Azevedo JC, Cobucci RN, DE Carvalho MG, Andrade VS and DE Araújo JM: Link between chronic inflammation and human papillomavirusinduced carcinogenesis (Review). Oncol Lett 9: 1015-1026, 2015.

26. He G and Karin M: NF- $\kappa$ B and STAT3 - key players in liver inflammation and cancer. Cell Res 21: 159-168, 2011.

27. Vreys V and David G: Mammalian heparanase: What is the message? J Cell Mol Med 11: 427-452, 2007.

28. Chang YH, Yu CW, Lai LC, Tsao CH, Ho KT, Yang SC, Lee H, Cheng YW, Wu TC and Shiau MY: Up-regulation of interleukin-17 expression by human papillomavirus type 16 E6 in nonsmall cell lung cancer. Cancer 116: 4800-4809, 2010.

29. Hirshoren N, Bulvik R, Neuman T, Rubinstein AM, Meirovitz A and Elkin M: Induction of heparanase by HPV E6 oncogene in head and neck squamous cell carcinoma. J Cell Mol Med 18: 181-186, 2014.

30. Bowers JS, Nelson MH, Kundimi S, Bailey SR, Huff LW, Schwartz KM, Cole DJ, Rubinstein MP and Paulos CM: Dendritic cells in irradiated mice trigger the functional plasticity and antitumor activity of adoptively transferred Tc17 cells via IL12 signaling. Clin Cancer Res 21: 2546-2557, 2015.

31. Yan B, Liu Y, Bai H, Chen M, Xie S, Li D, Liu M and Zhou J: HDAC6 regulates IL-17 expression in T lymphocytes: Implications for HDAC6-targeted therapies. Theranostics 7: 1002-1009, 2017

32. Lin Z, Bazzaro M, Wang MC, Chan KC, Peng S and Roden RB: Combination of proteasome and HDAC inhibitors for uterine cervical cancer treatment. Clin Cancer Res 15: 570-577, 2009.

33. Pikarsky E, Porat RM, Stein I, Abramovitch R, Amit S, Kasem S, Gutkovich-Pyest E, Urieli-Shoval S, Galun E and Ben-Neriah Y: NF-kappaB functions as a tumour promoter in inflammationassociated cancer. Nature 431: 461-466, 2004. 